\title{
High Prevalence of Vitamin D Deficiency among Bangladeshi Children: An Emerging Public Health Problem
}

\author{
Sanjana Zaman', Mohammad Delwer Hossain Hawlader ${ }^{1}$, Animesh Biswas ${ }^{2}$, Mahmudul Hasan", \\ Mobashera Jahan' ${ }^{1}$, Gias U Ahsan'
}

${ }^{1}$ Department of Public Health, North South University, Dhaka, Bangladesh

${ }^{2}$ Center for Injury Prevention and Research, Dhaka, Bangladesh

Email: *mohammad.hawlader@northsouth.edu

How to cite this paper: Zaman, S., Hawlader, M.D.H., Biswas, A., Hasan, M., Jahan, M. and Ahsan, G.U (2017) High Prevalence of Vitamin D Deficiency among Bangladeshi Children: An Emerging Public Health Problem. Health, 9, 1680-1688.

https://doi.org/10.4236/health.2017.912123

Received: October 22, 2017

Accepted: November 27, 2017

Published: November 30, 2017

Copyright $(9) 2017$ by authors and Scientific Research Publishing Inc. This work is licensed under the Creative Commons Attribution International License (CC BY 4.0).

http://creativecommons.org/licenses/by/4.0/

\begin{abstract}
Background: Recent studies suggested that vitamin D deficiency among children is widespread worldwide. Most of the Asian countries are suffering from high prevalence of vitamin D deficiency, especially in children. However, the vitamin D deficiency of Bangladeshi children has not been investigated yet. The objective of the study was to assess the prevalence of vitamin D deficiency among children in Dhaka city, Bangladesh. Methods: A cross-sectional study was designed. Children aged 0 month to 16 years attended Pediatrics' clinics with minor illness were conveniently recruited. After obtaining informed written consent, venous blood was taken and serum 25(OH)D levels were determined by direct enzyme-linked immunosorbent assay. Descriptive statistics were performed for age, sex, biochemical parameters. Socio-economic status (SES) was estimated using a wealth index, producing a weighted score. Scores were categorized into quintiles, with category 1 representing the poorest and category 5 the richest. Serum $25(\mathrm{OH}) \mathrm{D}$ was categorized: deficient as $<10 \mathrm{ng} / \mathrm{ml}$, insufficient as $10-29 \mathrm{ng} / \mathrm{ml}$ and sufficient as $30-100 \mathrm{ng} / \mathrm{ml}$. Results: $31.88 \%$ children of $0-1$ year had deficient serum 25(OH)D level and 52.17\% children had insufficient level. Among 2 - 5 years' group, $38.16 \%$ were deficient and $50 \%$ were insufficient. Among the $6-11$ years group, $41.02 \%$ were deficient and $52.56 \%$ were insufficient. Among 12 16 years group, $46.75 \%$ were deficient and $51.95 \%$ were insufficient. That means, serum 25-hydroxyvitamin D deficiency and insufficiency rate is found very high among Bangladeshi children. Conclusions: The prevalence of vitamin D deficiency and insufficiency among children in Bangladesh is high. The study recommended that vitamin D supplementation in Bangladeshi children should be formally launched from first day of birth up to adolescence.
\end{abstract}




\section{Keywords}

Prevalence, Serum 25(OH)D, Vitamin D, Children, Deficiency, Bangladesh

\section{Introduction}

Vitamin D is known as "the Sunshine Vitamin". The major source of vitamin D for most human is exposure to sunlight. With exposure to ultraviolet (UV) radiation, vitamin D3 is synthesized in human skin via the photoisomerization of 7-dehydrocholesterol (7DHC) which ultimately produces previtamin D3 [1]. Exposure to the amount of sunlight that causes a slight pinkness of the skin after 24 hours (1MED) is equivalent to ingesting approximately 20,000 IU of vitamin $\mathrm{D}$ [2]. Very few foods naturally contain vitamin $\mathrm{D}$ such as salmon, sardines, Tuna, Mackerel, shitake mushroom, hardboiled egg and foods that are fortified with vitamin D as like milk, cereal, orange juice, yogurt, and margarine. But those are inadequate to satisfy the requirement of vitamin $\mathrm{D}$ among children and adult [3]. Vitamin D deficiency causes rickets among children although rickets represents only the tip of the vitamin $\mathrm{D}$ deficiency iceberg. The vitamin $\mathrm{D}$ receptor is distributed in the osteoblasts, small intestine, colon, activated $\mathrm{T}$ and $\mathrm{B}$ lymphocytes, $\mathrm{b}$ islet cells, mononuclear cells and most other organs in the human body including the brain, heart, skin, gonads, prostate, and breast [4]. In recent years, there has been lots of study regarding the influence of vitamin D on extra skeletal health, besides skeletal health. Hypovitaminosis D may be associated with diabetes mellitus [5] [6], cancers [7], autoimmune diseases [8] [9], infectious diseases [10], multiple sclerosis [11] and other cardiovascular diseases [12].

Nowadays, vitamin D deficiency is a silent and neglected global public health issue. Almost one billion people in the world suffer from vitamin D deficiency or insufficiency [13]. There is a misconception that vitamin D deficiency is prevalent only in western countries, but in practical field it is totally reverse. Previously, it was assumed that hypovitaminosis $\mathrm{D}$ is less frequent in tropical countries, as cutaneous vitamin D synthesis is stimulated by exposure to sun. But, surprisingly $80 \%$ of the apparently healthy population is deficient in vitamin $\mathrm{D}$ $(<20 \mathrm{ng} / \mathrm{mL})$ and up to $40 \%$ of the population is severely deficient $(<10 \mathrm{ng} / \mathrm{mL})$ in South Asia [14]. Rickets is still widespread in regions, in northern China where $42 \%$ of infants were found to suffer from Rickets which occurs as a consequence of vitamin $\mathrm{D}$ deficiency during winter and spring season [15]. According to Siddiqui and Rai in Northern Pakistan, despite of abundant sunlight, rickets was a common problem in infants and children due to malnutrition, lack of awareness and antenatal factors [16]. High prevalence of vitamin D deficiency in South Asia can be explained by skin pigmentation and traditional clothing. Moreover, air pollution and limited outdoor activity is also responsible for this in the urban population [17]. In Japan, the status of vitamin D is relatively better 
than other regions of South Asia due to high sea fish consumption [18].

Although there is no definite cut off point for the optimal levels of 25-hydroxyvitamin D as measured in serum. According to most expert opinion, vitamin $\mathrm{D}$ deficiency is defined as a 25 -hydroxyvitamin $\mathrm{D}$ level of less than 50 nmol per liter [19], which is equivalent to $20 \mathrm{ng} / \mathrm{ml}$. In children, due to fewer outcome data, the optimal level of serum 25(OH)D for general health is not known yet. Moreover, it is controversial than in adults [20] [21]. It is evident that biochemical squeal of vitamin D deficiency may appear at cutoff levels of 75 $\mathrm{nmol} / \mathrm{L}$ [22] [23]. Expert opinion suggested that the minimal optimal circulating vitamin D level should be increased from $50 \mathrm{nmol} / \mathrm{L}$ to $75 \mathrm{nmol} / \mathrm{L}$ [24] [25]. The level of 25-hydroxyvitamin D between $50 \mathrm{nmol} / \mathrm{L}$ and $75 \mathrm{nmol} / \mathrm{L}$ can be considered as a relative insufficiency of vitamin $\mathrm{D}$ in children.

As per above mentioned definitions, the prevalence of vitamin $\mathrm{D}$ insufficiency was higher among American children aged 6 - 11 years (73\%) compared with children aged 1 - 5 years (63\%); girls (71\%) compared with boys (67\%); and non-Hispanic black (92\%) and Hispanic (80\%) children compared with non-Hispanic white children (59\%) [26]. Several other studies suggest that the prevalence of vitamin D insufficiency among children is 30\% - 50\% in Australia, Turkey, India, and Lebanon [27] [28] [29].

Considering the report from other Asian countries, it is assumed that Bangladesh is at risk of rickets and other vitamin D deficiency related health consequences. But there is no study regarding Vitamin D deficiency in infant, preschool, school age and adolescence stages. Therefore, we aimed to determine the prevalence of vitamin D deficiency in children of Bangladesh.

\section{Methods}

Study type: A cross sectional study was performed.

Sampling place: Study participants for this study were chosen from a Paediatrics clinic.

Sampling technique:

A convenience sampling technique was used. Study recruited a total of 300 children from February 2017 to July 2017.

\section{Inclusion Criteria}

The children age ranged from 0 month to 16 years who came to the child health care clinic with minor symptoms were examined and venous blood were collected for 25(OH)D measurement.

\section{Exclusion Criteria}

Children who were already diagnosed as case of rickets or hypocalcaemia or any abnormality in liver or renal function, which might affect hydroxylation of vitamin D, calcium and phosphorus metabolism were excluded.

Anthropometry measurement 
Heights for all participants were measured using a wall mounted stadiometer and weights were measured using digital scales. Standard operational procedure (SOP) was followed to obtained anthropometric measurement. Standardization of all equipment was done on a regular basis for the consistency of data.

Information on socio-economic status was collected by questionnaire.

25-hydroxyvitamin D measurement

Measurement of circulating levels of 25-hydroxyvitamin D [25(OH)D] are the most reliable measure of overall vitamin D status [4]. There are several recognized methods available to measure serum $25(\mathrm{OH}) \mathrm{D}$. However, in Bangladesh, most commonly used technique is direct enzyme-linked immunosorbent assay. That's why this study chose this technique to measure the serum $25(\mathrm{OH}) \mathrm{D}$ levels. Also there are many ways to define deficient, insufficient and sufficient and in our study we categorized deficient as $<10 \mathrm{ng} / \mathrm{ml}$, insufficient as $10-29 \mathrm{ng} / \mathrm{ml}$ and sufficient as $30-100 \mathrm{ng} / \mathrm{ml}$.

Statistical analyses

Data were categorized and analyzed using SPSS for windows version 21.0. Descriptive statistics were performed for age, sex, biochemical parameters and lifestyle factors. Socio-economic status (SES) was estimated using a wealth index based on information about household assets and the related principal component analysis, producing a weighted score. Scores were categorized into quintiles, with category 1 representing the poorest and category 5 the richest.

Ethical consideration

This study was approved by the ethical review committee of North South University, Dhaka, Bangladesh. Privacy and anonymity of the participants were maintained.

\section{Results}

Characteristics of the study participants:

A total of 300 children aged 0 month to 16 years participated. The participants were divided into four groups according to their ages: $0-1 \mathrm{y}, 2-5 \mathrm{y}, 6-11 \mathrm{y}$ and $12-16$ y as infant, preschool, primary, and secondary school stages respectively. Table 1 shown that, female participants (51.33\%) were little bit higher than the male participants (48.66\%). Study participants were almost equally distributed in different groups, $23.00 \%$ were 0 - 1 year, $25.33 \%$ were 2 - 5 years, $26.00 \%$ were 6 - 11 years and $25.67 \%$ were 12 - 16 years. That means there were no major differences among the groups. Participants height and weight was $108.85 \pm 55.86$ $\mathrm{cm}($ mean $\pm \mathrm{SD})$ and $18.2 \pm 21.21 \mathrm{~kg}$ (mean $\pm \mathrm{SD}$ ) respectively. According to wealth index, participants were distributed almost equally in different socio-economic category (Table 1).

Serum 25-hydroxyvitamin D levels

The distribution of serum 25-hydroxyvitamin $\mathrm{D}$ levels according to different age groups. It has been shown that, among 0 - 1 year group, $31.88 \%$ were deficient, majority (52.17\%) were insufficient and $15.94 \%$ were sufficient. Among 2 - 
Table 1. Characteristics of the study participants.

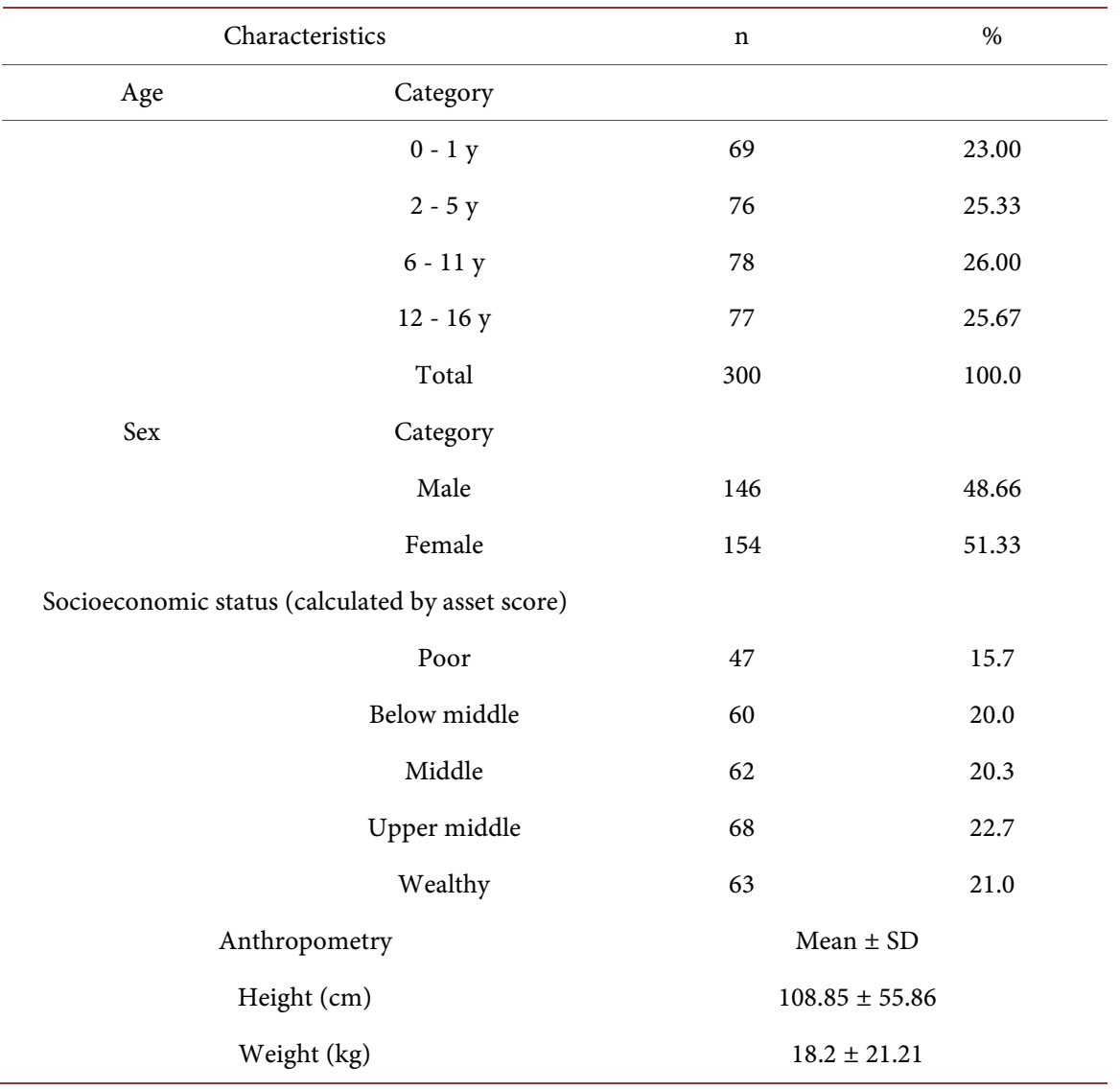

5 years, $38.16 \%$ were deficient, similar to previous group majority (50.00\%) were insufficient and only $11.84 \%$ were sufficient. Among the 6 - 11 years group $41.02 \%$ were deficient, $52.56 \%$ were insufficient and few of them $(6.41 \%)$ were sufficient. Lastly among 12 - 16 years group, $46.75 \%$ were deficient, 51.95\% were insufficient and only $1.30 \%$ were sufficient. That means, serum 25-hydroxyvitamin D deficiency rate is very high among Bangladeshi children and insufficiency is increased as age progress (Table 2).

\section{Discussions}

The study found that on an average almost $80 \%$ of Bangladeshi children are vitamin $\mathrm{D}$ deficient where the study applied the definition of vitamin deficiency $[25(\mathrm{OH}) \mathrm{D}<10 \mathrm{ng} / \mathrm{mL}]$. From this finding study can say that the vitamin $\mathrm{D}$ status of children in Bangladesh is poor. Bangladeshi People are at risk of vitamin $\mathrm{D}$ deficiency and vitamin $\mathrm{D}$ related other health consequences. In our study we found that the serum 25-hydroxyvitamin D levels among pediatric population gradually decreases as the age of the children gradually increases so the prevalence of vitamin D deficiency increased as the children became older. There is augmentation of both maternal and cord-blood $25(\mathrm{OH}) \mathrm{D}$ by antenatal vitamin D supplementation [30]. According to another study, it is documented that the 
Table 2. Serum 25-hydroxyvitamin D levels by age group.

\begin{tabular}{cccc}
\hline Age & $\begin{array}{c}<0 \mathrm{ng} / \mathrm{ml} \\
\mathrm{N}, \%\end{array}$ & $\begin{array}{c}10-29 \mathrm{ng} / \mathrm{ml} \\
\mathrm{N}, \%\end{array}$ & $\begin{array}{c}30-100 \mathrm{ng} / \mathrm{ml} \\
\mathrm{N}, \%\end{array}$ \\
\hline $0-1 \mathrm{y}$ & $22(31.88)$ & $36(52.17)$ & $11(15.94)$ \\
$2-5 \mathrm{y}$ & $29(38.16)$ & $38(50.00)$ & $9(11.84)$ \\
$6-11 \mathrm{y}$ & $32(41.02)$ & $41(52.56)$ & $5(06.41)$ \\
$12-16 \mathrm{y}$ & $36(46.75)$ & $40(51.95)$ & $1(01.30)$ \\
\hline
\end{tabular}

Bangladeshi infants start their life with poor vitamin D level due to low maternal antenatal $25(\mathrm{OH}) \mathrm{D}$, documented in urban and rural Bangladeshi women of reproductive age [31]. A study of India $\left(18^{\circ} \mathrm{N}\right)$, reveals that $51 \%$ had values of $25(\mathrm{OH}) \mathrm{D}<37.5 \mathrm{nmol} / \mathrm{L}$ among 35 three months aged breastfed infants and they had a mean 25(OH)D of $49 \mathrm{nmol} / \mathrm{L}$ [32]. In Pakistan $\left(25^{\circ} \mathrm{N}\right), 38$ six months aged breastfed infants had a mean $25(\mathrm{OH}) \mathrm{D}$ of $25 \mathrm{nmol} / \mathrm{L}(18 \mathrm{SD})$, and $71 \%$ of infants $(12 / 17)$ aged less than three months, had $25(\mathrm{OH}) \mathrm{D}<40 \mathrm{nmol} / \mathrm{L}$ [33]. Furthermore, another study from middle east shows that 78 infant, aged 1 - 4 months breastfed term infants, born to women with low milk intake and a habitual practice of covering the skin entirely when outdoors, $82 \%$ had $25(\mathrm{OH}) \mathrm{D}<25 \mathrm{nmol} / \mathrm{L}$ and had a median 25(OH)D of $11.5 \mathrm{nmol} / \mathrm{L}$ [34]. If we compare our data with the data of an American study, our children had much higher prevalence of vitamin $\mathrm{D}$ deficiency than the American children and adolescents. American Academy of Pediatrics released a new recommendation in November 2008, that all children should receive $400 \mathrm{IU} /$ day of vitamin D from their first day of life through adolescence [35]. So we suggest the recommendation on vitamin D supplementation for Bangladeshi pediatric population should be implemented because vitamin D deficiency is more severe than that of American children and then many other ethnic groups.

We have some limitations in our present study. The subjects were not sampled from the whole paediatric population in Bangladesh. As well as possible relating factors of vitamin D status including intake of supplements, life style, food habit related data were not collected. A further study based on subjects sampled on a population basis would be carried out and the possible relating factors of vitamin D should be explored. On the other hand, some authors warned about the prevalence of vitamin $\mathrm{D}$ deficiency was over estimated and the evidence of the role of vitamin D for extra-skeletal outcomes was inconsistent and inconclusive and for the conclusion, it need to be assessed by more randomized clinical trials [36] [37].

\section{Conclusions}

The prevalence of vitamin D deficiency and insufficiency among children in Bangladesh is very high and alarming. Further study is required to explore among the national representative samples. Moreover, since it is important for the growth and development of child, the country needs to develop comprehen- 
sive action plan to prevent such deficiency. We strongly recommend the vitamin D supplementation for Bangladeshi children from day 0 to adolescent and its implementation as early as possible from the government level. Besides that, developing awareness regarding Vitamin $\mathrm{D}$ should be expanded and fortification of food like milk, oil, yogurt, cereal as well as quality controlling assurance of the fortification is the prime need for the prevention of vitamin D deficiency and its related consequences in Bangladesh.

\section{References}

[1] Webb, A.R. (2006) Who, What, Where and When-Influences on Cutaneous Vitamin D Synthesis. Progress in Biophysics and Molecular Biology, 92, 17-25. https://doi.org/10.1016/j.pbiomolbio.2006.02.004

[2] Holick, M.F. (2010) Vitamin D: Extra Skeletal Health. Endocrinology and Metabolism Clinics of North America, 39, 381-400. https://doi.org/10.1016/j.ecl.2010.02.016

[3] Holick, M.F. and Chen, T.C. (2008) Vitamin D Deficiency: A Worldwide Problem with Health Consequences. The American Journal of Clinical Nutrition, 87, 1080S-1086S.

[4] Misra, M., Pacaud, D., Petryk, A., Collett-Solberg, P.F. and Kappy, M. (2008) Vitamin D Deficiency in Children and Its Management: Review of Current Knowledge and Recommendations. Pediatrics, 122, 398-417. https://doi.org/10.1542/peds.2007-1894

[5] Pittas, A.G., Lau, J., Hu, F.B. and Dawson-Hughes, B. (2007) The Role of Vitamin D and Calcium in Type 2 Diabetes. A Systematic Review and Meta-Analysis. The Journal of Clinical Endocrinology and Metabolism, 92, 2017-2029. https://doi.org/10.1210/jc.2007-0298

[6] Svoren, B.M., Volkening, L.K., Wood, J.R. and Laffel, L.M. (2009) Significant Vitamin D Deficiency in Youth with Type 1 Diabetes Mellitus. The Journal of Pediatrics, 154, 132-134. https://doi.org/10.1016/j.jpeds.2008.07.015

[7] Garland, C.F., Gorham, E.D., Mohr, S.B. and Garland, F.C. (2009) Vitamin D for Cancer Prevention: Global Perspective. Annals of Epidemiology, 19, 468-483. https://doi.org/10.1016/j.annepidem.2009.03.021

[8] Cutolo, M. and Otsa, K. (2008) Review: Vitamin D, Immunity and Lupus. Lupus, 17, 6-10. https://doi.org/10.1177/0961203307085879

[9] Al Nozha, O.M. (2016) Vitamin D and Extra-Skeletal Health: Causality or Consequence. International Journal of Health Sciences (Qassim), 10, 443-452.

[10] Cannell, J.J., Vieth, R., Umhau, J.C., Holick, M.F., Grant, W.B., et al. (2006) Epidemic Influenza and Vitamin D. Epidemiology and Infection, 134, 1129-1140. https://doi.org/10.1017/S0950268806007175

[11] Munger, K.L., Zhang, S.M., O’Reilly, E., Hernan, M.A., Olek, M.J., et al. (2004) Vitamin D Intake and Incidence of Multiple Sclerosis. Neurology, 62, 60-65. https://doi.org/10.1212/01.WNL.0000101723.79681.38

[12] Wang, T.J., Pencina, M.J., Booth, S.L., Jacques, P.F., Ingelsson, E., et al. (2008) Vitamin D Deficiency and Risk of Cardiovascular Disease. Circulation, 117, 503-511. https://doi.org/10.1161/CIRCULATIONAHA.107.706127

[13] Holick, M.F. (2007) Vitamin D Deficiency. The New England Journal of Medicine, 357, 266-281. https://doi.org/10.1056/NEJMra070553

[14] Arya, V., Bhambri, R., Godbole, M.M. and Mithal, A. (2004) Vitamin D Status and 
Its Relationship with Bone Mineral Density in Healthy Asian Indians. Osteoporosis International, 15, 56-61. https://doi.org/10.1007/s00198-003-1491-3

[15] Strand, M.A., Perry, J., Jin, M., Tracer, D.P., Fischer, P.R., Zhang, P., et al. (2007) Diagnosis of Rickets and Reassessment of Prevalence among Rural Children in Northern China. Pediatrics International, 49, 202-209. https://doi.org/10.1111/j.1442-200X.2007.02343.x

[16] Siddiqui, T.S. and Rai, M.I. (2005) Presentation and Predisposing Factors of Nutritional Rickets in Children of Hazara Division. Journal of Ayub Medical College, 17, 29-32.

[17] Agarwal, K.S., Mughal, M.Z., Upadhyay, P., et al. (2002) The Impact of Atmospheric Pollution on Vitamin D Status of Infants and Toddlers in Delhi India. Archives of Disease in Childhood, 87, 111-113. https://doi.org/10.1136/adc.87.2.111

[18] Nakamura, K., Nashimoto, M., Okuda, Y., Ota, T. and Yamamoto, M. (2002) Fish as a Major Source of Vitamin Din the Japanese Diet. Nutrition, 18, 415-416.

[19] Holick, M.F. (2006) High Prevalence of Vitamin D Inadequacy and Implications for Health. Mayo Clinic Proceedings, 81, 353-373. https://doi.org/10.4065/81.3.353

[20] Hollis, B.W. (2005) Circulating 25-Hydroxyvitamin D Levels Indicative of Vitamin D Sufficiency: Implications for Establishing a New Effective Dietary Intake Recommendation for Vitamin D. Journal of Nutrition, 135, 317-322.

[21] Greer, F.R. (2003) Vitamin D Deficiency-It's More than Rickets. Journal of Pediatrics, 143, 422-423. https://doi.org/10.1067/S0022-3476(03)00465-7

[22] Bischoff-Ferrari, H.A., Giovannucci, E., Willett, W.C., Dietrich, T. and Dawson-Hughes, B. (2006) Estimation of Optimal Serum Concentrations of 25-Hydroxyvitamin D for Multiple Health Outcomes. The American Journal of Clinical Nutrition, 84, 18-28.

[23] Maalouf, J., Nabulsi, M., Vieth, R., Kimball, S., El-Rassi, R., Mahfoud, Z. and El-Hajj Fuleihan, G. (2008) Short- and Long-Term Safety of Weekly High-Dose Vitamin D3 Supplementation in School Children. The Journal of Clinical Endocrinology \& Metabolism, 93, 2693-2701. https://doi.org/10.1210/jc.2007-2530

[24] Holick, M.F. (2007) Vitamin D Deficiency. The New England Journal of Medicine, 357, 266-281. https://doi.org/10.1056/NEJMra070553

[25] Yetley, E.A. (2008) Assessing the Vitamin D Status of the US Population. The American Journal of Clinical Nutrition, 88, 558-564.

[26] Mansbach, J.M., Ginde, A.A. and Camargo, C.A. (2009) Serum 25-Hydroxyvitamin D Levels among US Children Aged 1 to 11 Years: Do Children Need More Vitamin D. Pediatrics, 124, 1404-1410. https://doi.org/10.1542/peds.2008-2041

[27] Marwaha, R.K., Tandon, N., Reddy, D.R., Aggarwal, R., Singh, R., Sawhney, R.C., Saluja, B., Ganie, M.A. and Singh, S. (2005) Vitamin D and Bone Mineral Density Status of Healthy Schoolchildren in Northern India. The American Journal of Clinical Nutrition, 82, 477-482.

[28] El-Hajj, F.G., Nabulsi, M., Choucair, M., Salamoun, M., Hajj Shahine, C., Kizirian, A. and Tannous, R. (2001) Hypovitaminosis D in Healthy Schoolchildren. Pediatrics, 107, 53. https://doi.org/10.1542/peds.107.4.e53

[29] McGrath, J.J., Kimlin, M.G., Saha, S., Eyles, D.W. and Parisi, A.V. (2001) Vitamin D Insufficiency in South-East Queensland. The Medical Journal, 174, 150-151.

[30] Specker, B. (2004) Vitamin D Requirements during Pregnancy. The American Journal of Clinical Nutrition, 80, 1740S-1747S.

[31] Islam, M.Z., Lamberg-Allardt, C., Karkkainen, M., Outila, T., Salamatullah, Q. and 
Shamim, A.A. (2002) Vitamin D Deficiency: A Concern in Premenopausal Bangladeshi Women of Two Socio-Economic Groups in Rural and Urban Region. European Journal of Clinical Nutrition, 56, 51-56.

https://doi.org/10.1038/sj.ejcn.1601284

[32] Bhalala, U., Desai, M., Parekh, P., Mokal, R. and Chheda, B. (2007) Subclinical Hypovitaminosis D among Exclusively Breastfed Young Infants. Indian Pediatrics, 44, 897-901.

[33] Atiq, M., Suria, A., Nizami, S.Q. and Ahmed, I. (1998) Maternal Vitamin D Deficiency in Pakistan. Acta Obstetricia et Gynecologica Scandinavica, 77, 970-973. https://doi.org/10.1080/j.1600-0412.1998.771004.x

[34] Dawodu, A., Agarwal, M., Hossain, M., Kochiyil, J. and Zayed, R. (2003) Hypovitaminosis D and Vitamin D Deficiency in Exclusively Breast-Feeding Infants and Their Mothers in Summer: A Justification for Vitamin D Supplementation of Breast-Feeding Infants. Journal of Pediatrics, 142, 169-173.

https://doi.org/10.1067/mpd.2003.63

[35] Wagner, C.L. and Greer, F.R. (2008) Prevention of Rickets and Vitamin D Deficiency in Infants, Children, and Adolescents. Pediatrics, 122, 1142-1152.

https://doi.org/10.1542/peds.2008-1862

[36] Ross, A.C., Manson, J.E., Abrams, S.A., Aloia, J.F., Brannon, P.M., Clinton, S.K., Durazo-Arvizu, R.A., Gallagher, J.C., Gallo, R.L., Jones, G., Kovacs, C.S., Mayne, S.T., Rosen, C.J. and Shapses, S.A. (2011) The 2011 Report on Dietary Reference Intakes for Calcium and Vitamin D from the Institute of Medicine: What Clinicians Need Toknow. The Journal of Clinical Endocrinology \& Metabolism, 96, 53-58. https://doi.org/10.1210/jc.2010-2704

[37] Chung, M., Balk, E.M., Brendel, M., Ip, S., Lau, J., Lee, J., Lichtenstein, A., Patel, K., Raman, G., Tatsioni, A., Terasawa, T. and Trikalinos, T.A. (2012) Vitamin D and Calcium: A Zhu et al. BMC Public Health, 12, 126.

https://doi.org/10.1186/1471-2458-12-126 